\title{
(6) OPEN ACCESS \\ Lumbar spine bone mineral density Z-score discrepancies by dual X-ray absorptiometry do not predict vertebral fractures in children
}

\author{
Tasma Harindhanavudhi, ${ }^{1}$ Anna Petryk, ${ }^{2,3}$ Richard Jones, ${ }^{4}$ \\ Amanda Regodón Wallin, ${ }^{5}$ James $S$ Hodges, ${ }^{6}$ Sara Van Nortwick, \\ Bradley S Miller, ${ }^{2}$ Tara L Holm, ${ }^{4}$ Kyriakie Sarafoglou ${ }^{2}$
}

${ }^{1}$ Division of Diabetes and Endocrinology, Department of Medicine, University of Minnesota, Minneapolis, Minnesota, USA

${ }^{2}$ Division of Pediatric Endocrinology, Department of Pediatrics, University of Minnesota, Minneapolis,

Minnesota, USA

${ }^{3}$ Alexion Pharmaceuticals,

Inc., New Haven,

Connecticut, USA

${ }^{4}$ Division of Pediatric Radiology, Department of Radiology, University of Minnesota, Minneapolis, Minnesota, USA ${ }^{5}$ Karolinska Institutet, Stockholm, Sweden ${ }^{6}$ Division of Biostatistics, School of Public Health, University of Minnesota, Minneapolis, Minnesota, USA

${ }^{7}$ Department of Orthopaedic Surgery, University of Minnesota, Minneapolis, Minnesota, USA

\section{Correspondence to} Dr Tasma Harindhanavudhi, Division of Diabetes and Endocrinology, Department of Medicine, University of Minnesota, Minneapolis MN 55455, USA:

hari0049@umn.edu

Accepted 18 March 2018 Published Online First 4 April 2018

\begin{abstract}
Dual X-ray absorptiometry (DXA) remains the most common mode of bone mineral density (BMD) evaluation. In adults, presence of a lumbar spine (LS) BMD T-score discrepancy (>1SD difference between adjacent vertebrae) can indicate a vertebral fracture. In children, however, the clinical significance of such discrepancies is unknown. We conducted a retrospective study to evaluate the association between LS DXA and LS morphology to elucidate the clinical significance of an LS BMD Z-score discrepancy. We identified 360 DXA scans performed between September 2014 and May 2016 in patients 5-18years of age. DXA scans were cross-referenced against available $L S$ radiographs and vertebral fracture assessment (VFA) within the 6 months preceding or following a DXA scan. After excluding 44 DXA scans because of spinal hardware, incomplete DXA, or repeat scans, 316 DXA scans were included; 81 (25.6\%) had either an LS radiograph or a VFA. Twenty-five of 81 patients (30.9\%) had >1 SD difference between adjacent vertebrae in LS BMD Z-score. Two of these 25 patients $(8 \%)$ had a lumbar vertebral fracture documented by a spine radiograph. Of the remaining 56 patients who did not have a discrepancy $>1$ SD, 6 patients (11\%) had a lumbar vertebral fracture. Discrepancies in LS BMD Z-scores were not associated with lumbar vertebral fractures and, in the absence of fractures, likely represented vertebral developmental variants in children whose skeletons are still growing. Therefore, it does not appear justified to recommend further imaging based solely on the results of a DXA scan without clinically meaningful indications.
\end{abstract}

\section{INTRODUCTION}

Dual X-ray absorptiometry (DXA) is the most commonly used mode of evaluation of bone mineral density (BMD) in children and adults due to widely accessible normative data, low radiation exposure, and ease of administration. A child's bones, unlike an adult's, grow and reshape over time and the growth of individual bones is not uniform in three dimensions, confounding DXA interpretation. Because

\section{Significance of this study}

What is already known about this subject?

- Dual X-ray absorptiometry (DXA) is the most commonly used mode of evaluation of bone mineral density (BMD) in children and adults.

- A discrepancy in BMD T-scores (>1 SD difference between adjacent vertebrae) commonly indicates structural abnormalities especially vertebral compression fractures or spinal degenerative changes in adults.

- The International Society for Clinical Densitometry's Pediatric Official Positions statement does not provide any guidance on the interpretation of a discrepancy in Z-scores ( $>1$ SD between adjacent vertebrae) when measuring BMD.

What are the new findings?

- A discrepancy in lumbar BMD Z-scores ( $>1$ SD difference between adjacent vertebrae) was not associated with lumbar vertebral fracture in children.

- L1 was most commonly identified as the lumbar vertebra with the highest BMD Z-score. Therefore, it may be more appropriate to use the $\mathrm{L} 2-\mathrm{L} 4$ average rather than the $\mathrm{L} 1-\mathrm{L} 4$ average for reporting lumbar BMD Z-scores in children.

- The variation of lumbar vertebra BMD Z-scores, in the absence of fracture, likely represented developmental variants in children whose skeletons are still growing.

How might these results change the focus of research or clinical practice?

- Further lumbar spine imaging to rule out vertebral fractures in children with a discrepancy in lumbar BMD Z-scores does not appear to be warranted based solely on the result of a DXA scan unless clinically indicated.

of this variability in skeletal development in growing children, the posterior-anterior lumbar spine (LS) and total body less head are preferred 
when measuring BMD with DXA in children. ${ }^{12}$ Z-scores, not T-scores, are preferred for children or premenopausal women and men $<50$ years old to compare the person's BMD with the average BMD for the person's age, sex, and race. T-score is used for postmenopausal women or men $\geq 50$ years old and compares the person's BMD with a healthy Caucasian woman aged $20-29$ years old. ${ }^{3}$

The 2015 International Society for Clinical Densitometry's (ISCD) Adult Official Positions statement ${ }^{3}$ recommended that when interpreting BMD measurements for L1-L4 vertebrae in adults, vertebrae should be excluded from analysis if there is (1) a focal structural defect within the vertebral body, (2) no increase in bone mineral content or bone area from L1 to L4, or (3) $>1$ SD difference between adjacent vertebrae in T-scores. ${ }^{34}$ Such a discrepancy in T-scores commonly indicates structural abnormalities especially vertebral compression fractures or spinal degenerative changes that tend to falsely elevate BMD. ${ }^{56}$ In clinical practice, a spinal radiograph or vertebral fracture assessment (VFA) could be obtained to further evaluate vertebral morphology if falsely elevated BMD is suspected. VFA may serve as a useful screen for fractures in adults with height loss, especially because the ionizing radiation dose to the patient is very small compared with radiography. ${ }^{13}$

However, the clinical significance of LS BMD discrepancies in children is still unclear. Unlike the guideline for adults, the 2013 ISCD's Pediatric Official Positions statement does not provide any guidance on the interpretation of a discrepancy in Z-score (>1SD) between adjacent vertebrae when measuring BMD for L1-L4 vertebrae. ${ }^{12}$ In the absence of such recommendations, the question arises whether the interpretation and significance of discrepancy in LS BMD in adults ${ }^{56}$ should be applied to children. Therefore, this study's aim was to determine the clinical significance in children of discrepancies $>1$ SD between adjacent vertebral Z-scores from LS DXA results in association with lumbar vertebral morphology (by either a spine radiograph or VFA).

\section{MATERIALS AND METHODS Patients}

A retrospective chart review was performed to identify patients between 5 and 18 years inclusive who underwent a DXA scan between September 2014 and May 2016 at an academic pediatric hospital. We identified patients who had an LS radiograph or VFA within 6 months of a DXA scan; only a minority of these examinations preceded the DXA scan. LS radiograph or VFA was obtained because of the patient's underlying diseases, such as surveillance after organ transplantation or exposure to chronic glucocorticoid use. Individual lumbar vertebral $Z$-scores were recorded to identify a discrepancy in Z-score ( $>1 \mathrm{SD}$ ) between adjacent vertebrae, and LS radiographs or VFAs were reviewed by $\mathrm{RJ}$ to determine whether lumbar vertebral fractures were present. DXA and VFA measurements were obtained using a Prodigy DXA scanner (GE, Lunar, Madison, Wisconsin, USA). The DXA scans were analyzed using the manufacturer's pediatric software, except for the VFA. Vertebral fracture severity by VFA was assessed by a pediatric radiologist using the semiquantitative method of Genant $e t a l^{7}$ rather than the manufacturer's software due to limited accuracy of the software in outlining vertebral bodies, particularly in young children. The following grades were used based on the reduction in anterior (wedge), middle (biconcave), and posterior (crush) vertebral height: normal (grade 0), mild deformity (grade 1) approximately 20\%-25\%, moderate deformity (grade 2) approximately $25 \%-40 \%$, and severe fracture (grade 3 ) approximately $>40 \%$. Reports for DXA were made by either of two pediatric endocrinologists with more than 10 years' experience (BSM or AP) or by a pediatric radiologist (TH, 10 years' experience). VFA reports were made by a pediatric radiologist $(\mathrm{TH})$. Radiograph reports were made by one of four pediatric radiologists with 6-10years' experience. No additional adjustments for height or bone age were performed because Z-score differences between individual vertebrae were assessed in the same individual and not compared between individuals.

Demographic data and medical history were recorded, including comorbidities, fracture history, and exposure to glucocorticoids and other medications with a potential impact on bone health, such as luteinizing hormone-releasing hormone agonists, aromatase inhibitors, and antiseizure drugs.

\section{Statistical analyses}

Subgroups of children were compared using Fisher's exact test for categorical characteristics (eg, sex, referral diagnoses) and two-sample t-tests for continuous characteristics (eg, age). The CI for relative risk used the back-transformed large-sample interval for the log relative risk. All statistical analyses were done in JMP (V.12.0 Pro, SAS Institute, Cary, North Carolina). p Values $<0.05$ were deemed statistically significant.

\section{RESULTS}

A total of 360 DXA scans were performed in children (5-18 years of age inclusive) from September 2014 through May 2016 (figure 1). Forty-four DXA scans were excluded due to previous spinal surgery, spinal instrumentation, unavailable spinal DXA picture/data, or because the child had multiple scans (when a child had more than one scan, only the first one was included). Out of 316 remaining DXA scans, a discrepancy in LS BMD Z-scores (>1SD) was observed in 53 children (17\%). The vertebra with the highest LS BMD Z-score was most commonly L1 (50.6\% of children), followed by L3 (36.1\%), L4 (17.1\%), and L2 (10.1\%). For 41 children, two or more vertebrae had LS BMD Z-score equal to the highest LS BMD Z-score.

Of 316 DXA scans, 81 (25.6\%) had a comparison study and 235 (74.4\%) had no comparison study (figure 1). Of the 81 DXA scans with comparison studies, 8 (9.9\%) were compared with both VFA and LS radiography, 34 (42.0\%) were compared only with VFA, and 39 (48.1\%) were compared with LS radiography. Table 1 shows the characteristics of these 81 children. Overall, the children had an average age of 12.0 (SD 4.2) years; 51.8\% (42 children) were male and most were Caucasian. Sex and ethnicity did not differ significantly between children who had a discrepancy in LS BMD Z-scores (>1SD) and those who did not (table 1). Patients with a discrepancy in LS BMD Z-scores were younger than those without a discrepancy. A similar trend was observed in the entire study population 


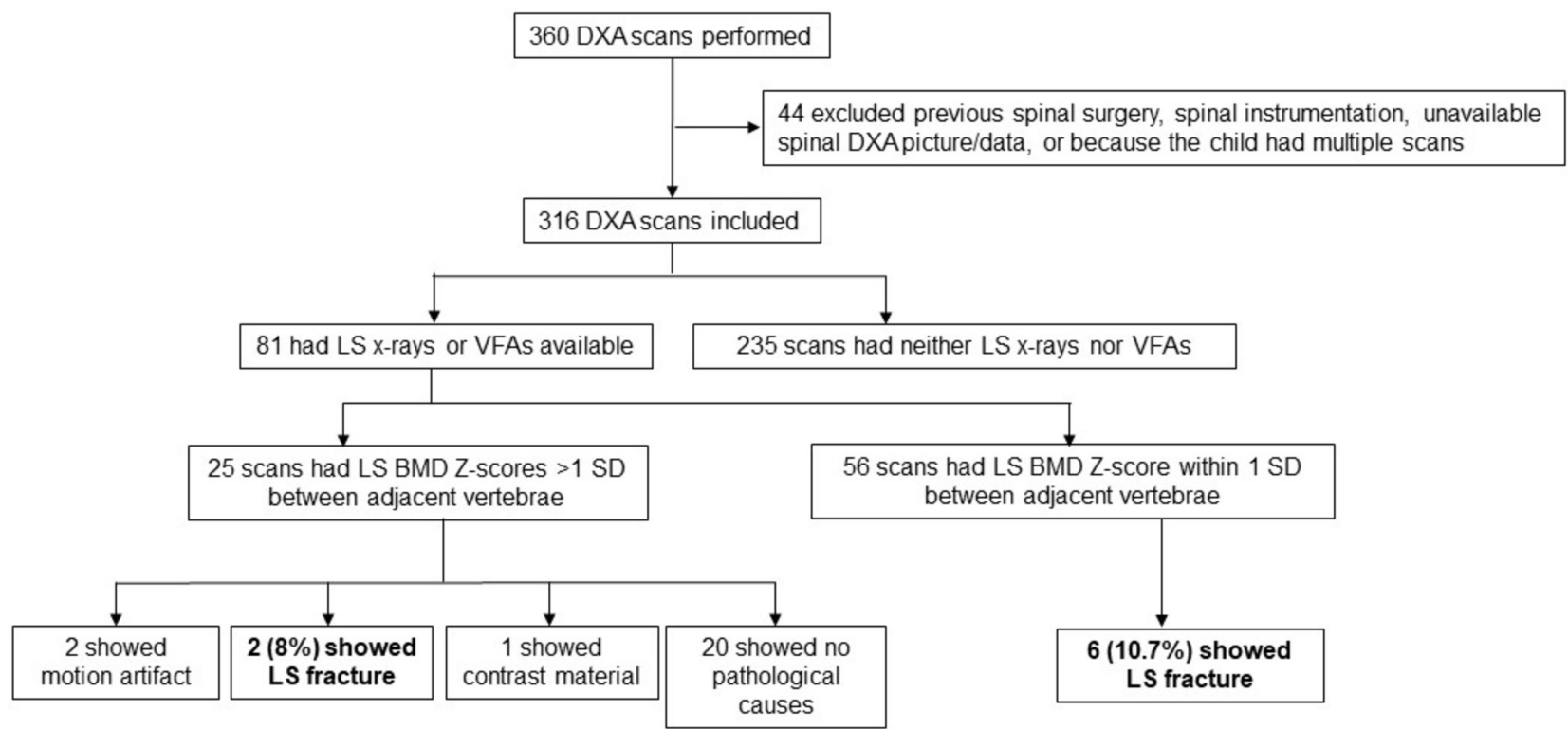

Figure 1 Flow chart of the study. DXA, dual X-ray absorptiometry; LS, lumbar spine; VFA, vertebral fracture assessment.

$(\mathrm{n}=316)$ : an LS BMD Z-score discrepancy was observed in $27 \%(26 / 96)$ of those younger than 11 years and $12 \%$ $(27 / 220)$ of those 11 years and older $(p=0.0018)$, although logistic regression analyses showed a steady decline with age in frequency of discrepancy and not a sharp change at age 11. Table 1 lists the indications for DXA scan; the most common referral diagnoses were history of transplant (bone marrow, heart, and kidney), followed by endocrine diseases, neuromuscular diseases, and genetic diseases, likely because our institute is a large referral center for hematopoietic and solid organ transplantation. Thirty-six (44.4\%) children were on glucocorticoids, and 4 (5\%) children were on other medications including leuprolide, anastrozole, and phenytoin. The remaining children were not on medications impacting bone metabolism.

Among those 81 DXA scans with a comparison radiograph or VFA, 25 (30.9\%) showed a discrepancy in LS BMD Z-scores, and only 2 of those 25 patients (8\%) had a lumbar vertebral fracture documented by a spine radiograph or VFA (figure 1). Of the remaining 56 patients who did not have a discrepancy in LS BMD Z-scores, 6 (10.7\%) had lumbar vertebral fractures. The relative risk of a fracture for children with versus without a discrepancy was 0.75 (95\% CI 0.16 to 3.4 ), that is, the association is in the wrong direction. Table 2 shows the DXA characteristics of the two patients with identified lumbar vertebral fractures. Patient 1 had mild wedge fracture of L1 vertebra identified by a spinal radiograph in concordance with the DXA scan, which measured the highest BMD Z-score at L1. In patient 2, mild wedge fractures were identified by a spinal radiograph in L1 and L2 but not in L3, where the DXA scan measured the highest BMD Z-score. Table 3 shows the characteristics of patients who had lumbar vertebral fractures identified by either VFA or LS radiograph without LS Z-score discrepancy by DXA scan. In children who had a discrepancy in lumbar BMD Z-scores and had no identifiable fractures, other causes of discrepancy in BMD Z-scores included motion artifact (two cases) and contrast material (one case).
However, there were no identifiable pathologic causes of a discrepancy in lumbar BMD Z-scores in the remaining 20 DXA scans. Scoliosis was not detected in any of the DXA scans that showed LS BMD Z-scores discrepancy.

\section{DISCUSSION}

We found that a discrepancy in lumbar BMD Z-scores (>1SD difference between adjacent vertebrae) was not associated with lumbar vertebral fracture in children. Only 2 of 25 patients (8\%) who had lumbar BMD Z-score discrepancy identified by DXA scan had a lumbar vertebral fracture, while 6 of $56(11 \%)$ with no discrepancy had a lumbar vertebral fracture. The two children who had both discrepancies and fractures had associated comorbidities as they both were postheart transplant, with one having growth hormone deficiency and the other delayed puberty and chronic glucocorticoid use. In one of these patients, the lumbar vertebra with the highest BMD Z-score was not the fractured vertebra.

Our study's results are consistent with a previous study in adults by Morgan et al, ${ }^{8}$ which found that a lumbar T-score discrepancy with no increase in bone area and bone mineral content from L1 to L4 did not predict lumbar vertebral fracture assessed by VFA. Instead, the presence of lumbar scoliosis was associated with lumbar T-score discrepancy. ${ }^{8}$ In our study, no lumbar scoliosis was present in children whose DXA scans had a discrepancy in lumbar BMD Z-scores. Another study in early postmenopausal women found wide variability of individual T-scores and BMD within the LS and lack of association with the presence of degenerative spinal disease or vertebral fractures. ${ }^{9}$

Unlike adults, in children a discrepancy in lumbar BMD Z-scores may not always indicate vertebral fracture. Rather, it may represent the physiologic developmental process of the vertebrae in growing children, or its disruption or delay by a chronic illness or its treatment, which could mimic vertebral fracture or abnormal vertebrae and lead to 
Table 1 Characteristics of patients who had DXA scan and either lumbar spine radiograph or vertebral fracture assessment for comparison

\begin{tabular}{|c|c|c|c|}
\hline Characteristics & $\begin{array}{l}\text { Patients with } \\
\text { L1-L4 BMD } \\
\text { Z-score }>1 \text { SD } \\
\text { difference } \\
\text { between } \\
\text { adjacent } \\
\text { vertebrae }(n=25)\end{array}$ & $\begin{array}{l}\text { Patients with } \\
\text { L1-L4 BMD } \\
\text { Z-score within } \\
1 \text { SD between } \\
\text { adjacent } \\
\text { vertebrae }(n=56)\end{array}$ & $\mathrm{p}$ Values \\
\hline Age & 10.4 (SD 4.0) & 12.7 (SD 4.5) & 0.03 \\
\hline Male & $14(56 \%)$ & $28(50 \%)$ & 0.64 \\
\hline \multicolumn{4}{|l|}{ Ethnicity } \\
\hline Non-Hispanic Caucasian & $23(92 \%)$ & $53(95 \%)$ & 0.64 \\
\hline Others & $2(8 \%)$ & $3(5 \%)$ & \\
\hline \multicolumn{4}{|l|}{ Referral diagnoses for DXA } \\
\hline $\begin{array}{l}\text { Post-transplantation, } \\
\text { chemotherapy, and } \\
\text { radiation* }\end{array}$ & $14(56 \%)$ & $23(39 \%)$ & 0.65 \\
\hline Primary bone diseasest & $2(8 \%)$ & $7(13 \%)$ & \\
\hline Endocrine disease $\ddagger$ & $4(16 \%)$ & $12(21 \%)$ & \\
\hline Others§ & $5(20 \%)$ & $15(27 \%)$ & \\
\hline \multicolumn{4}{|l|}{ Relevant medications } \\
\hline Glucocorticoids & $10(40 \%)$ & $26(46 \%)$ & 0.64 \\
\hline Others** & $0(0 \%)$ & $4(7 \%)$ & 0.31 \\
\hline No relevant medications & $15(60 \%)$ & $28(50 \%)$ & 0.47 \\
\hline
\end{tabular}

*Bone marrow, heart, and kidney transplantation.

†Osteogenesis imperfecta, osteoporosis, and multiple stress fractures. ‡Non-classical congenital adrenal hyperplasia, hyperthyroidism, premature pubarche, premature adrenarche, precocious puberty, primary ovarian failure, panhypopituitarism, Turner syndrome, growth hormone deficiency, adrenal insufficiency, and gender identity disorder.

$\S$ Duchenne muscular dystrophy, dermatomyositis, thalassemia, cerebral palsy, limb-girdle muscular dystrophy, chromosomal abnormality (5.6 Mb duplication from 9q22.33 to 9q31.1 and $202 \mathrm{~Kb}$ duplication at 17p13.3), complex neurodevelopmental disease, cystic fibrosis, hypercalciuria, prematurity, Opitz trigonocephaly C syndrome, and Morquio A syndrome. \$2 children were on both categories of medications.

${ }^{* *}$ Anastrozole, leuprolide, and phenytoin.

BMD, bone mineral density; DXA, dual X-ray absorptiometry.

misdiagnosis. In the Canada-wide Steroid-associated Osteoporosis in Pediatric Population observational study of 400 children who had thoracolumbar spine radiographs annually for 6 years, researchers identified a variety of common vertebral developmental changes of the anterior, central, and posterior vertebral body mimicking vertebral fractures such as physiologic wedging, variants in the ring apophyses, vertebral artery impression, Cupid's bow, Schmorl's node, or trapezoidal L5. ${ }^{10}$

In the absence of specific practice guidelines for children regarding interpretation of variability in individual BMD $\mathrm{Z}$-scores, the great variability in children's BMD Z-scores creates uncertainty whether to exclude an individual vertebra that shows a BMD Z-score that is disproportionately high compared with the other lumbar vertebrae. In other studies, individual lumbar vertebral BMD variation was very common in adults, ${ }^{11-13}$ and using individual lumbar vertebral BMD had diagnostic sensitivity inferior to using the average L1-L4 value. ${ }^{12}$ Peel $e t ~ a l^{11}$ found that L1 was incorrectly identified on DXA scans in up to $13 \%$ of cases in adults and that the impact of this was reduced if $\mathrm{L} 2-\mathrm{L} 4$ was analyzed as an area of interest instead of L1-L4. In our study, L1 was most commonly identified as the lumbar vertebra with the highest BMD Z-score, followed by L3, L4, and L2. Therefore, it may be more appropriate to use the L2-L4 average rather than the L1-L4 average for reporting lumbar BMD Z-scores in children. L1-L4 BMD may be an overestimate, and potentially lead to a diagnostic misclassification of a patient as having normal BMD versus low BMD.

VFA assesses lateral vertebral morphology using DXA and thus involves lower radiation exposure than spine radiography. VFA has been widely used to evaluate vertebral fractures in adults. Several studies have evaluated the utility of VFA versus spine radiograph in children, with mixed results. Mäyränpää et $a l^{14}$ demonstrated limited accuracy of VFA in vertebral fracture detection (only $36 \%$ of vertebral fractures were detected by VFA) due to poor visibility from intrathoracic tissue and diaphragmatic movement. However, more recent studies in children showed reliable diagnostic performance of VFA as a screening tool for vertebral fracture. ${ }^{1516}$ Additionally, studies in adults and children with osteogenesis imperfecta found that VFA had comparable diagnostic accuracy when compared with LS radiograph in detecting moderate to severe vertebral fracture but was suboptimal in mild vertebral deformity. ${ }^{17-19}$ While VFA is promising as a low-radiation imaging modality to screen for vertebral fractures in children, it is not currently recommended by the ISCD's Pediatric guidelines.

Our study has several limitations, largely due to its retrospective design. Relative homogeneity of race and ethnicity, with the majority of study subjects being Caucasian, could limit generalizability. Vertebral morphology could only be assessed in a subgroup of patients (25.6\%) with available confirmatory radiographs and/or VFAs that could lead

Table 2 Characteristics of patients who had DXA scan with lumbar spine Z-score discrepancy and vertebral fractures identified by either VFA or lumbar spine radiograph

\begin{tabular}{|c|c|c|c|c|c|c|c|c|c|c|c|}
\hline \multirow[b]{2}{*}{ Patient } & \multirow{2}{*}{$\begin{array}{l}\text { Age } \\
\text { (years) }\end{array}$} & \multirow{2}{*}{$\begin{array}{l}\text { Highest } \\
\text { lumbar spine } \\
\text { (DXA) }\end{array}$} & \multicolumn{4}{|c|}{ BMD Z-scores } & \multirow[b]{2}{*}{ VFA } & \multirow[b]{2}{*}{ X-ray } & \multirow{2}{*}{$\begin{array}{l}\text { Fracture by } \\
\text { X-ray }\end{array}$} & \multirow[b]{2}{*}{ Type } & \multirow[b]{2}{*}{ Referral diagnoses } \\
\hline & & & L1 & L2 & L3 & L4 & & & & & \\
\hline 1 & 12 & L1 & -2.0 & -3.6 & -3.4 & -2.9 & Not done & Yes & $\mathrm{L} 1$ & $\begin{array}{l}\text { Mild (grade 1) } \\
\text { wedge fracture of L1 }\end{array}$ & $\begin{array}{l}\text { Post heart transplant, } \\
\text { growth hormone } \\
\text { deficiency }\end{array}$ \\
\hline 2 & 17 & L3 & -2.8 & -1.7 & -0.5 & -2.8 & Not done & Yes & L1, L2 & $\begin{array}{l}\text { Mild (grade 1) } \\
\text { wedge fracture of L1 } \\
\text { and L2 }\end{array}$ & $\begin{array}{l}\text { Post heart transplant, } \\
\text { chronic glucocorticoid } \\
\text { use, delayed puberty }\end{array}$ \\
\hline
\end{tabular}

DXA, dual X-ray absorptiometry; VFA, vertebral fracture assessment. 
Table 3 Characteristics of patients who had lumbar vertebral fractures identified by either VFA or lumbar spine radiograph without lumbar spine Z-score discrepancy by DXA scan

\begin{tabular}{|c|c|c|c|c|c|c|c|c|c|c|c|}
\hline \multirow[b]{2}{*}{ Patient } & \multirow{2}{*}{$\begin{array}{l}\text { Age } \\
\text { (years) }\end{array}$} & \multirow{2}{*}{$\begin{array}{l}\text { Highest } \\
\text { lumbar } \\
\text { spine (DXA) }\end{array}$} & \multicolumn{4}{|c|}{ BMD Z-scores } & \multirow[b]{2}{*}{ VFA } & \multirow[b]{2}{*}{ X-ray } & \multirow[b]{2}{*}{ Fracture } & \multirow[b]{2}{*}{ Type } & \multirow[b]{2}{*}{ Referral diagnoses } \\
\hline & & & L1 & L2 & L3 & L4 & & & & & \\
\hline 1 & 5 & 0.3 & 0.3 & 0.2 & 0 & 0 & $\begin{array}{l}\text { Not } \\
\text { done }\end{array}$ & Yes & L1, L5 & $\begin{array}{l}\text { Mild (grade 1) wedge } \\
\text { fracture of } L 1 \text {, mild (grade } \\
\text { 1) crush fracture of } L 5\end{array}$ & Recurrent multiple fractures \\
\hline 2 & 8 & -2.3 & -2.3 & -3.1 & -2.7 & -3.3 & Yes & Yes & L1-L5 & $\begin{array}{l}\text { Moderate (grade } 2 \text { ) wedge } \\
\text { fracture of } L 1-L 2 \text {, mild } \\
\text { (grade 1) wedge fracture } \\
\text { of } L 3-L 5\end{array}$ & Post heart transplant \\
\hline 3 & 12 & -2.0 & -2.2 & -2.5 & -2.0 & -2.8 & Yes & No & L1 & $\begin{array}{l}\text { Mild (grade 1) wedge } \\
\text { fracture of L1 }\end{array}$ & $\begin{array}{l}\text { Opitz trigonocephaly C syndrome, } \\
\text { vitamin D deficiency }\end{array}$ \\
\hline 4 & 13 & -1.2 & -1.4 & -1.5 & -1.2 & -1.7 & Yes & Yes & L2 & $\begin{array}{l}\text { Mild (grade 1) biconcave } \\
\text { fracture of L2 }\end{array}$ & Delayed puberty, short stature \\
\hline 5 & 14 & -1.8 & -1.8 & -2.8 & -2.8 & -2.5 & $\begin{array}{l}\text { Not } \\
\text { done }\end{array}$ & Yes & L1-L5 & $\begin{array}{l}\text { Severe (grade 3) wedge } \\
\text { fracture of } \mathrm{L} 1 \text {, moderate } \\
\text { (grade 2) wedge fracture } \\
\text { of } \mathrm{L} 2-\mathrm{L} 5\end{array}$ & $\begin{array}{l}\text { Duchenne muscular dystrophy, } \\
\text { short stature, chronic } \\
\text { glucocorticoid use }\end{array}$ \\
\hline 6 & 16 & -1.4 & -2.2 & -1.4 & -2.1 & -2.4 & Yes & $\begin{array}{l}\text { Not } \\
\text { done }\end{array}$ & L2 & $\begin{array}{l}\text { Mild (grade 1) wedge } \\
\text { fracture of } L 2\end{array}$ & $\begin{array}{l}\text { Complex neurodevelopmental } \\
\text { syndrome, seizure, developmental } \\
\text { delay, chronic phenytoin use }\end{array}$ \\
\hline
\end{tabular}

DXA, dual X-ray absorptiometry; VFA, vertebral fracture assessment.

to low prevalence of fractures. The decision to obtain a spinal radiograph or VFA was at the discretion of the referring clinician based on the clinical history and individual patient's risk. Referral diagnoses for performing DXA scans, radiographs, and VFAs varied and included a large proportion of organ transplant recipients managed by specialists in tertiary care setting, which could have led to selection bias and limited generalizability.

In conclusion, this study did not find an association between a discrepancy in lumbar BMD Z-score of $>1$ SD between adjacent vertebrae by a DXA scan and vertebral fracture by radiography or VFA. This variation of lumbar vertebra BMD likely represented developmental variants in children. Therefore, it does not appear to be justified to recommend further LS imaging based solely on a discrepancy of lumbar BMD Z-score on a DXA scan. However, if clinical suspicion for vertebral fractures exists based on signs and symptoms in high-risk patients, further evaluation is necessary to rule out vertebral fractures.

Correction notice This article has been corrected since it was published Online First. An additional affiliation has been added for author Anna Petryk. The author name 'Amanda R Wallin' has been corrected to 'Amanda Regodón Wallin'.

Contributors AP and KS designed the study. TH, AP, RJ, ARW, and SVN collected data for the study. TH, AP, and KS wrote the paper. JSH performed data analysis. TH, AP, JSH, BSM, TLH, and KS revised the manuscript.

Funding Research reported in this publication was partially supported by the National Cancer Institute of the National Institutes of Health under award number R01CA181024 to KS.

Competing interests None declared.

Patient consent Detail has been removed from this case description/these case descriptions to ensure anonymity. The editors and reviewers have seen the detailed information available and are satisfied that the information backs up the case the authors are making.

Ethics approval The study was approved by the University of Minnesota Institutional Review Board (IRB code number: 1605M87566).

Provenance and peer review Not commissioned; externally peer reviewed.
Open access This is an open access article distributed in accordance with the Creative Commons Attribution Non Commercial (CC BY-NC 4.0) license, which permits others to distribute, remix, adapt, build upon this work noncommercially, and license their derivative works on different terms, provided the original work is properly cited and the use is non-commercial. See: http:// creativecommons.org/licenses/by-nc/4.0/

(c) American Federation for Medical Research (unless otherwise stated in the text of the article) 2018. All rights reserved. No commercial use is permitted unless otherwise expressly granted.

\section{REFERENCES}

1 Crabtree NJ, Arabi A, Bachrach LK, et al. Gordon CM International Society for Clinical Densitometry. J Clin Densitom 2014;17:225-42.

2 ISCD Official Positions for Pediatrics. 2013 http://www.iscd.org/officialpositions/2013-iscd-official-positions-pediatric/ (assessed on 28 Sep 2017).

3 ISCD Official Positions for Adults. 2015 https://www.iscd.org/official-positions/ 2015-iscd-official-positions-adult/ (assessed on 28 Sep 2017).

4 Hamdy RC, Petak SM, Lenchik L.International Society for Clinical Densitometry Position Development Panel and Scientific Advisory Committee. Which central dual X-ray absorptiometry skeletal sites and regions of interest should be used to determine the diagnosis of osteoporosis? J Clin Densitom 2002;5:S11-7.

5 Ryan PJ, Evans P, Blake GM, et al. The effect of vertebral collapse on spinal bone mineral density measurements in osteoporosis. Bone Miner 1992;18:267-72.

6 Rand T, Seidl G, Kainberger F, et al. Impact of spinal degenerative changes on the evaluation of bone mineral density with dual energy $X$-ray absorptiometry (DXA). Calcif Tissue Int 1997;60:430-3.

7 Genant HK, Wu CY, van Kuijk C, et al. Vertebral fracture assessment using a semiquantitative technique. J Bone Miner Res 1993;8:1137-48.

8 Morgan SL, Lopez-Ben R, Nunnally N, et al. Nonprogression of vertebral area or bone mineral content on DXA does not predict compression fractures. J Clin Densitom 2006;9:261-4.

9 Sahota O, Pearson D, Cawte SW, et al. Site-specific variation in the classification of osteoporosis, and the diagnostic reclassification using the lowest individual lumbar vertebra T-score compared with the L1-L4 mean, in early postmenopausal women. Osteoporos Int 2000;11:852-7.

10 Jaremko J, Siminoski K, Firth G, et al. for Canadian STOPP Consortium National Pediatric Bone Health Working Group Common normal variants of pediatric vertebral development that mimic fractures: a pictorial review from a national longitudinal bone health study. Pediatr Radio/ 2005;45:593-605.

11 Peel NF, Johnson A, Barrington NA, et al. Impact of anomalous vertebral segmentation on measurements of bone mineral density. J Bone Miner Res 1993;8:719-23.

12 Ryan PJ, Blake GM, Herd R, et al. Distribution of bone mineral density in the lumbar spine in health and osteoporosis. Osteoporos Int 1994;4:67-71. 
13 Mylonakis A, Hadjidakis D, Katsavochristos P, et al. Discrepancies between vertebral bone density values: the least dense vertebra. Maturitas 2006;53:476-82.

14 Mäyränpää MK, Helenius I, Valta $\mathrm{H}$, et al. Bone densitometry in the diagnosis of vertebral fractures in children: accuracy of vertebral fracture assessment. Bone 2007;41:353-9.

15 Kyriakou A, Shepherd S, Mason A, et al. A critical appraisal of vertebral fracture assessment in paediatrics. Bone 2015:81:255-9.

16 Crabtree NJ, Chapman S, Högler W, et al. Vertebral fractures assessment in children: Evaluation of DXA imaging versus conventional spine radiography. Bone 2017;97:168-74.
17 Schousboe JT, Debold CR. Reliability and accuracy of vertebral fracture assessment with densitometry compared to radiography in clinical practice. Osteoporos Int 2006;17:281-9.

18 Diacinti D, Pisani D, D'Avanzo M, et al. Reliability of vertebral fractures assessment (VFA) in children with osteogenesis imperfecta. Calcif Tissue Int 2015;96:307-12.

19 Binkley N, Krueger D, Gangnon R, et al. Lateral vertebral assessment: a valuable technique to detect clinically significant vertebral fractures. Osteoporos Int 2005;16:1513-8. 